\title{
GRM - Brainfuck
}

\section{Erhard Taverna}

Dr. med., Mitglied der Redaktion

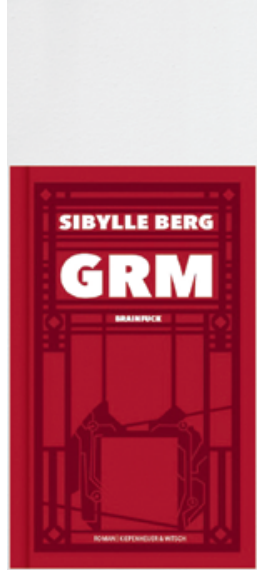

Autorin Sibylle Berg

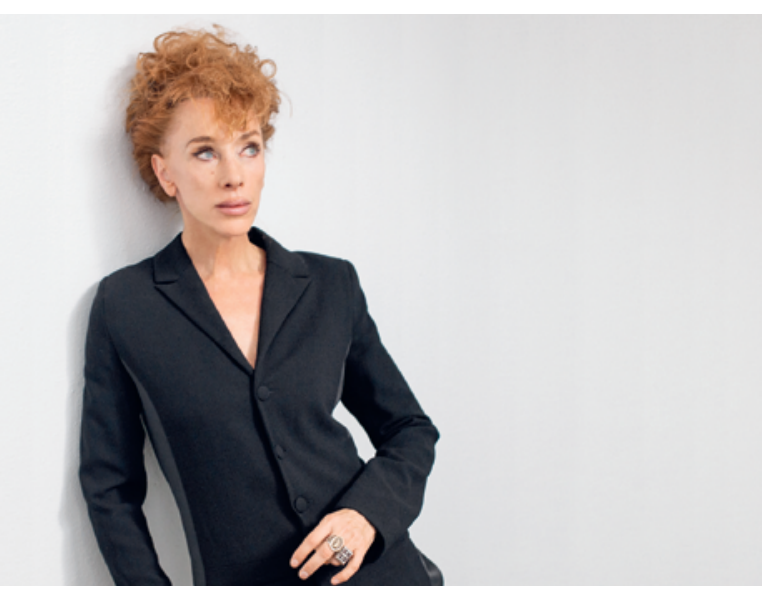

Ein Ausdruck für Grime, englisch für Schmutz, eine Variante des Gangster-Hip-Hop, gesungen zwischen Wut und Depression. Die Autorin Sibylle Berg, geboren 1962, lebt in Zürich, GRM - Brainfuck ist ihr neuester Roman. Die preisgekrönte Schriftstellerin ist durch zahlreiche Theaterstücke und in viele Sprachen übersetzte Romane bekannt geworden. Nichts von den schrecklichen Szenarien, die Dystopisten sich ausgedacht haben, sei eingetreten, schreibt sie. «Die Entwicklung der Welt ist elegant. Leise. Unauffällig.» Ein grimmiges Orakel des Spätkapitalismus, eine gute Dekade weitergedacht, hin auf einen elektronischen Überwachungstotalitarismus nach chinesischem Vorbild mit der Fassade eines ausgehöhlten Sozialstaates.

Sibylle Berg bekämpfte in einem Aktionskomitee die vom Bundesrat beschlossene, gesetzliche Grundlage für Sozialdedektive, die im November 2018 mit zwei Drittel der Stimmen angenommen wurde. "Wohl verloren. Berg weint», twitterte die Autorin nach der Niederlage. Noch viel weitreichendere Folgen werden die Abstimmungen über Kürzungen der Sozialhilfe haben. Dreissig Prozent weniger Geld für den Grundbedarf oder pro Tag und Person fünf Franken Essensgeld. Bern, Aargau und Baselland planen einschneidende Senkungen, die gemäss Caritas verfassungswidrig sind. Die düstere Verlängerung der Gegenwart lässt sich leicht auf Beschlüsse bürgerlich dominierter Parlamente zurückführen. Nach dem vollzogenen Brexit wird der Sozialabbau in Grossbritannien mit allen Konsequenzen vorangetrieben. Ausser in der Musik ist kein Platz für Träume. Kurze Steckbriefe leiten zu den Geschichten von Don, Hannah, Karen, Peter und den zahlreichen Nebenfiguren ein. Die Kinder wachsen auf im Armutsviertel von Rochdale bei
Manchester. Im Stich gelassen, verwahrlost und gedemütigt, geprägt von Sucht und Gewalt, kämpfen sie gegen Einsamkeit und Langeweile. Die Mütter sind überfordert, die Väter abwesend. Männer kommen schlecht weg, junge und alte aus allen Gesellschaftsschichten, triebgesteuert, aggressiv, absturzgefährdet und bösartig. Das Leben ist ein grausamer Überlebenskampf aller gegen alle, die Schulen kaputtgespart, das Gesundheitswesen verlottert. Dafür gibt es billig subventionierte Psychopharmaka. Russen und Chinesen haben das Zentrum Londons aufgekauft, Militär und Polizei sind privatisiert. Es wimmelt von Drohnen, wer sich einen Chip einpflanzen lässt, bekommt ein garantiertes Mindesteinkommen, das durch Bonus- und Maluspunkte reguliert wird. Eine knallharte, monströse Erzählung, die alle aktuellen Übel von Digitalisierung, Gentechnik und ökologischen Katastrophen weiterspinnt. Abstossend, ermüdend und überwältigend und bei allem Zynismus voller Erbarmen für diese Unterschicht-Menschlein, die einen hoffnungslosen Ausstieg versuchen. Ein Text, der durch die dunkelsten Winkel des Internets surft, brutal und oft kaum auszuhalten. Grossartig geschrieben, in

\section{Ein Text, der durch die dunkelsten Winkel des} Internets surft, brutal und oft kaum auszuhalten.

einem Textrhythmus, der mit seinen Zeilensprüngen an Lyrik und Sprechgesang erinnert, an Rap oder eben Grime. Der kommende Premierminister ist der Avatar einer IT-gesteuerten Klassengesellschaft mit einer degenerierten Oberschicht. Wer zu den Verlierern zählt, die absteigende Mittelschicht, Flüchtlinge, Illegale, Obdachlose, sie alle müssen verschwinden.

Oft möchte man das Buch mit seinen 632 Seiten weglegen, um sich den sanfteren Seiten unserer Noch-Privilegien zuzuwenden. Doch die Lektüre ist zu nahe an der Gegenwart geschrieben, sie nagt an unserem Gewissen, sofern dieses noch vorhanden ist. Was wir aus unserem Gesichtsfeld verdrängen, bricht mit Gewalt in unseren Alltag ein. Dass diese Zukunft den Enkeln erspart bleibe, ist die stille Hoffnung und Forderung dieses Werkes von Sibylle Berg.

\section{Bildnachweis \\ (c) Katharina Lütscher}

\section{Literatur}

Sibylle Berg, GRM - Brainfuck, Roman, Kiepenheuer\&Witsch, Köln, 1. Auflage 2019. 